\title{
Launching partnership in optics and photonics education between University of Rochester and Moscow Engineering Physics Institute NRNU MEPhl
}

Svetlana Lukishova, Irina Zavestovskaya, Xi-Cheng Zhang, Yury Aleshchenko, Vitaly Konov

Svetlana G. Lukishova, Irina N. Zavestovskaya, Xi-Cheng Zhang, Yury A. Aleshchenko, Vitaly I. Konov, "Launching partnership in optics and photonics education between University of Rochester and Moscow Engineering Physics Institute NRNU MEPhl," Proc. SPIE 10452, 14th Conference on Education and Training in Optics and Photonics: ETOP 2017, 1045226 (16 August 2017); doi: 10.1117/12.2269873

SDIE Event: 14th Conference on Education and Training in Optics and Photonics, ETOP 2017, 2017, Hangzhou, China 


\title{
Launching partnership in optics and photonics education between University of Rochester and Moscow Engineering Physics Institute NRNU MEPhI
}

\author{
Svetlana G. Lukishova*, Irina N. Zavestovskaya ${ }^{\mathrm{b}, \mathrm{c}}$, Xi-Cheng Zhang ${ }^{\mathrm{a}}$, \\ Yury A. Aleshchenko ${ }^{\text {b,c }}$, Vitaly I. Konov ${ }^{\text {b,d }}$ \\ ${ }^{a}$ The Institute of Optics, University of Rochester, Rochester NY, USA \\ ${ }^{b}$ National Research Nuclear University MEPhI, Moscow, Russia \\ ${ }^{c}$ Lebedev Physical Institute of the Russian Academy of Sciences, Moscow, Russia \\ ${ }^{\mathrm{d}}$ Prokhorov General Physics Institute of the Russian Academy of Sciences, Moscow, Russia \\ *E-mail:sluk@1le.rochester.edu
}

\begin{abstract}
A collaboration in education between the oldest and one of the most comprehensive Optics schools in U.S., the Institute of Optics (IO), University of Rochester (UR), and one of the most recognized Russian university, National Research Nuclear University MEPhI (Moscow Engineering Physics Institute) was started in 2015 by signing an agreement on a double-Master's degree program in optics. It was based on earlier collaboration between research groups in both universities. In summer of 2016, nine UR Optics undergraduate students participated with MEPhI students at the International School on Optics and Laser Physics in MEPhI. During five days they were immersed into the world of cutting edge research, technologies and ideas that Russian, European and U.S. scientists offered them. This School also included tours of MEPhI Nanotechnologies and Lasers Centers and Nano-bioengineering Laboratory as well as of scientific laboratories of the leading institutes in optics, photonics and laser physics of the Russian Academy of Sciences. In December of 2015, one MEPhI Master student visited IO UR for one month for a research project with results presented later at a MEPhI conference. Samples prepared by MEPhI researchers are used in IO students teaching laboratories. One Master student from MEPhI is working now towards the Master's degree at the IO UR. In this paper benefits and pitfalls of a cross-border collaboration are discussed as well as different directions of such a collaboration to provide a high-quality specialization for the students of the 21 century which includes international cooperation.
\end{abstract}

Keywords: Cross-border collaboration in education, a double-Master's degree program in optics, International School on Optics and Laser Physics in MEPhI, The Institute of Optics, University of Rochester, National Research Nuclear University MEPhI (Moscow Engineering Physics Institute).

\section{INTRODUCTION}

This paper outlines the efforts on launching long-term, mutually-beneficial cross-border partnership for two leading world schools in optics, photonics and lasers exploring its benefits as well as challenges. The University of Rochester (UR), USA, and the National Research Nuclear University MEPhI (NRNU MEPhI), Russia, established their cooperation in education based on earlier collaboration between research groups of these two universities. This collaborative activity was reported in Ref. [1].

Below in this Introduction (Sections 1.1 and 1.2), some information about two universities is provided. In Section 2, we describe a cross-border education by joint participation of students of both universities in the international summer School organized in Moscow, Russia as well as students' participation in collaborative research projects. A double Master's degree program between two universities will be discussed in Section 3. In Section 4 some other efforts in collaboration between the UR and Russian institutions will be discussed. Section 5 concludes this paper.

\subsection{The University of Rochester and the Institute of Optics (Rochester NY, U.S.)}

The University of Rochester (UR) [2] founded in 1850 is one of the U.S. leading private research universities. In its history, five university alumni have been awarded a Nobel Prize. In recent rankings of US News and World Report 2015, UR won

14th Conference on Education and Training in Optics and Photonics: ETOP 2017, edited by Xu Liu,

Xi-Cheng Zhang, Proc. of SPIE Vol. 10452, 1045226 · C 2017 ICO, IEEE, OSA, SPIE

CCC code: $0277-786 X / 17 / \$ 18 \cdot$ doi: $10.1117 / 12.2269873$ 
6th place in best graduate schools - physics (atomic, molecular, and optical) and 33rd place among national universities. Times Higher Education World Rankings (U.K.) 2013-2014 ranks UR as 95th among World universities.

The Institute of Optics of UR [3] was founded in 1929 as U.S. first educational program in optics. It is widely considered one of the U.S. premier optics schools. The Institute of Optics has granted over 2400 degrees in Optics, approximately half of all degrees awarded in Optics in the U.S. Key areas of faculty research are Optoelectronics \& Lasers, Ultrafast Optics \& High-Field Sciences (including laser plasmas, femtosecond laser ablation, terahertz technology), Nanooptics \& Nanophotonics, Quantum Optics, Optical Materials, Nonlinear Optics, Physical Optics, Fibers \& Optical Communications, Image Science \& Systems, Optical Engineering, Optical Fabrication, Vision \& Ophthalmic Optics, Biomedical Optics, Optics Education. Some Optics faculty members are affiliated with the Laboratory for Laser Energetics (LLE) of the UR and their students carry out research projects in this laboratory. LLE was established in 1970 at the UR as a center for the investigation of the interaction of laser radiation with matter to conduct experiments on National Inertial Confinement Fusion program, to develop new laser and materials technologies; to provide graduate and undergraduate education in high-power lasers, high-energy-density physics, plasma physics, and nuclear fusion technology.

\subsection{The National Research Nuclear University MEPhI (Moscow Engineering Physics Institute), (Moscow, Russia)}

The National Research Nuclear University (NRNU) MEPhI [4] received its name MEPhI (Moscow Engineering Physics Institute) in 1953, although it was founded in 1942. It is the most comprehensive Russian university in the field of nuclear physics and technology including laser-induced thermonuclear fusion. Among the MEPhI professors were six Nobel Prize winners and the founders of the Soviet nuclear physics and nuclear power industry. A new stage in the development of the university began in 2008, when MEPhI became one of the first two national research universities and was renamed the National Research Nuclear University "MEPhI". MEPhI takes the third place in the national rating of Russian universities 2012/13. MEPhI holds 36th place in recent Times Higher Education World Universities Rankings in the field of Physics.

Optics, photonics and laser physics at MEPhI were strengthened by Nobel prize winner Nikolaj Basov, a former MEPhI student, who organized a Special MEPhI Department (SD) based on his Quantum Radiophysics Division (QRD) of the Lebedev Physical Institute (LPI) of the Russian Academy of Sciences (RAS). In 2014, SD evolved to the Magistratura with its leaders having joint appointments in two leading laser, optics and photonics institutions of the RAS - LPI $[5,6]$ and the Prokhorov General Physics Institute (GPI) [7].

\section{CROSS-BORDER EDUCATION BY IMMERSING STUDENTS TO THE CUTTING-EDGE SCIENCE AND TECHNOLOGY ABROAD}

\subsection{The International School on Optics and Laser Physics at NRNU MEPhI (May 2016, Moscow, Russia)}

In May of 2016, nine UR Optics undergraduate students participated in the International School on Optics and Laser Physics at MEPhI that was organized by the Magistratura of MEPhI (I.N. Zavestovskaya and Yu.S. Aleshchenko). From the UR this trip was organized and supervised by S.G. Lukishova. For almost a week both UR and MEPhI students were immersed into the world of cutting edge research, technologies and ideas that Russian, European and US scientists offered them at this School (see Figures 1-3 showing participants, speakers and organizers of this School). The School also included tours of MEPhI Nanotechnologies and Lasers Centers and the Nano-bioengineering Laboratory as well as LPI QRD and GPI laboratories of RAS. UR students learned about NRNU MEPhI and its Institute for Laser and Plasma Technologies, about laser activity in LPI QRD, carbon photonics, luminescent nanodiamond biomarkers, optical diagnostics of CVD diamond growth, organic nanophotonics, linear and nonlinear optical effects on the interfaces of nanoand biological systems, optical chemical and bio sensing, novel materials and methods for bio-nanophotonics, laser thermonuclear fusion including cryogenic laser targets, history of injection lasers in LPI, hybrid (solid/gas) femtosecond systems in the visible, nonlinear propagation of femtosecond laser pulses in bulk silicon, laser printing of plasmonic nanostructures, modeling of nanomaterials' optical properties, nonclassical light sources, what is the photon including single-photon interference experiments with delayed choice, and the history of relationship between USA and Russian Federation. During two days the lectures were delivered at LPI RAS, so students learned its history with 7 Nobel prize winners, started from the collection ("cabinet") of scientific devices and instruments in St-Petersburg (from year of 1727) and founded as a Moscow institution in year of 1934 by S.I. Vavilov, its first director [6].

Table 1 presents the scientific program of the School. In addition, the excursions paid by MEPhI were organized on Moscow and its history. UR students lived at MEPhI dormitory, and lodging expenses and meal inside the MEPhI were covered by MEPhI. MEPhI Master's students helped to UR students in their accommodation in a new environment. 
Table 1. Program of the International School on Optics and Laser Physics (Moscow, 23-27 May 2016) 23 May 2016, Monday

\begin{tabular}{|l|l|}
\hline $09.00-10.00$ & $\begin{array}{l}\text { Registration of participants of the conference } \\
\text { Conference hall of 3rd floor of the Main building of MEPhI }\end{array}$ \\
\hline $10.00-10.20$ & Opening Ceremony. Oleg N. Krokhin, Nikolai I. Kargin \\
\hline Section 1 & Chairman: Alexei P. Menushenkov \\
\hline $10.20-10.40$ & $\begin{array}{l}\text { I.N. Zavestovskaya } \text { (LPI, MEPhI) « National Research Nuclear University MEPhI } \\
\text { (Moscow Engineering Physics Institute)» }\end{array}$ \\
\hline $10.40-11.20$ & Oleg N. Krokhin (LPI, MEPhI) «What is photon?» \\
\hline $11.20-11.40$ & Break \\
\hline $11.40-12.20$ & Andrey P. Kuznetsov (MEPhI) "Institute for laser and plasma technologies" \\
\hline $12.20-13.00$ & Svetlana G. Lukishova (UR,USA) "Nonclassical light sources: the science of darkness". \\
\hline $13.00-14.00$ & Lunch \\
\hline $14.00-17.00$ & The tour of the laboratories of MEPhI - Laser center \\
\hline
\end{tabular}

24 May 2016, Tuesday

\begin{tabular}{|l|l|}
\hline $09.00-10.00$ & $\begin{array}{l}\text { Registration of participants of the conference } \\
\text { Conference hall, 3rd floor of the Main building of P.N. Lebedev Physical Institute of the } \\
\text { RAS }\end{array}$ \\
\hline Section 2 & Chairman: Vitaly I. Konov \\
\hline $10.00-10.40$ & $\begin{array}{l}\text { Igor } \text { R. Nabiev (Reims Univ., France, MEPhI) «Linear and non-linear optical effects on } \\
\text { the interfaces of nano- and biological systems» }\end{array}$ \\
\hline $10.40-11.20$ & Igor I. Vlasov (GPI, MEPhI) «Luminescent nanodiamond biomarkers» \\
\hline $11.20-11.40$ & Break \\
\hline $11.40-12.20$ & Petr I. Nikitin (GPI, MEPhI) «Optical chemical and bio sensing» \\
\hline $12.20-13.00$ & V.Yu. Yurov (GPI) «Optical diagnostics of CVD diamond growth» \\
\hline $13.00-14.00$ & Lunch \\
\hline $14.00-17.00$ & The tour of the laboratories of Prokhorov General Physics Institute, RAS (GPI RAS) \\
\hline
\end{tabular}

25 May 2016, Wednesday

\begin{tabular}{|l|l|}
\hline $09.00-10.00$ & $\begin{array}{l}\text { Registration of participants of the conference } \\
\text { Conference hall, 3rd floor of the Main building of P.N. Lebedev Physical Institute of the } \\
\text { RAS }\end{array}$ \\
\hline Section 3 & Chairman: Leonid D. Mikheev \\
\hline $10.00-10.40$ & $\begin{array}{l}\text { Edward Lozansky «Relationship between USA and Russian Federation. Who is in fault } \\
\text { and que faire?» }\end{array}$ \\
\hline $10.40-11.20$ & Alexei Vitukhnovsky $($ LPI, MEPhI) «Organic nanophotonics» \\
\hline $11.20-11.40$ & Break \\
\hline $11.40-12.20$ & Evgeny V. Zavedeev $($ GPI) «Nonlinear propagation of fs laser pulses in silicon bulk» \\
\hline $12.20-13.00$ & $\begin{array}{l}\text { Andrey A. Ionin }(\text { LPI) "Laser activity at the Quantum Radiophysics Division of the } \\
\text { Lebedev Institute". }\end{array}$ \\
\hline $13.00-14.00$ & Lunch \\
\hline $14.00-17.00$ & $\begin{array}{l}\text { The tour of the laboratories of Quantum Radiophisics Department of P.N. Lebedev } \\
\text { Physical Institute of the RAS }\end{array}$ \\
\hline
\end{tabular}

26 May 2016, Thursday

\begin{tabular}{|l|l|}
\hline $09.00-10.00$ & $\begin{array}{l}\text { Registration of participants of the conference } \\
\text { Conference hall of the 7th floor of the building- } K \text { of } M E P h I\end{array}$ \\
\hline
\end{tabular}




\begin{tabular}{|l|l|}
\hline Section 4 & Chairman: Igor I. Yashin \\
\hline $10.00-10.40$ & $\begin{array}{l}\text { Yuriy M. Popov (LPI, MEPhI) "History of injection lasers in P.N. Lebedev Physical } \\
\text { Institute" }\end{array}$ \\
\hline $10.40-11.20$ & Sergei . Gus'kov (LPI, MEPhI) "Laser thermonuclear fusion" \\
\hline $11.20-11.40$ & Break \\
\hline $11.40-12.20$ & $\begin{array}{l}\text { Leonid D. Mikheev (LPI, MEPhI) «Hybrid (solid/gas) femtosecond systems in the } \\
\text { visible: architecture and applications» }\end{array}$ \\
\hline $12.20-13.00$ & $\begin{array}{l}\text { Elena } \text {. Koresheva (LPI, MEPhI) “Cryogenic laser targets for inertial confinement } \\
\text { fusion" }\end{array}$ \\
\hline $13.00-14.00$ & Lunch \\
\hline $14.00-17.00$ & The tour of the laboratories of MEPhI - scientific-educational center "Nanotechnologies" \\
\hline
\end{tabular}

27 May 2016, Friday

\begin{tabular}{|l|l|}
\hline $09.00-10.00$ & $\begin{array}{l}\text { Registration of participants of the conference } \\
\text { Conference hall of the 7th floor of the building-K of MEPhI }\end{array}$ \\
\hline Section 5 & Chairman: Andrey P. Kuznetsov \\
\hline $10.00-10.40$ & Yuri N. Kulchin (IPAU, Vladivostok, MEPhI)"Modern Photonics" \\
\hline $10.40-11.20$ & $\begin{array}{l}\text { Andrei } \text { V. Kabashin (Aix-Marseille University, France) "Novel Materials and Methods } \\
\text { for Bionanophotonics" }\end{array}$ \\
\hline $11.20-11.40$ & Break \\
\hline $11.40-12.20$ & Irina . Zavestovskaya (LPI, MEPhI) «Laser materials nanostructurization» \\
\hline $12.20-13.00$ & Alexander V. Osadchy (GPI,MEPhI) «Modeling of nanomaterials optical properties» \\
\hline $13.00-14.00$ & Lunch \\
\hline $14.00-17.00$ & The tour of the laboratory of nano-bioengineering of MEPhI \\
\hline
\end{tabular}

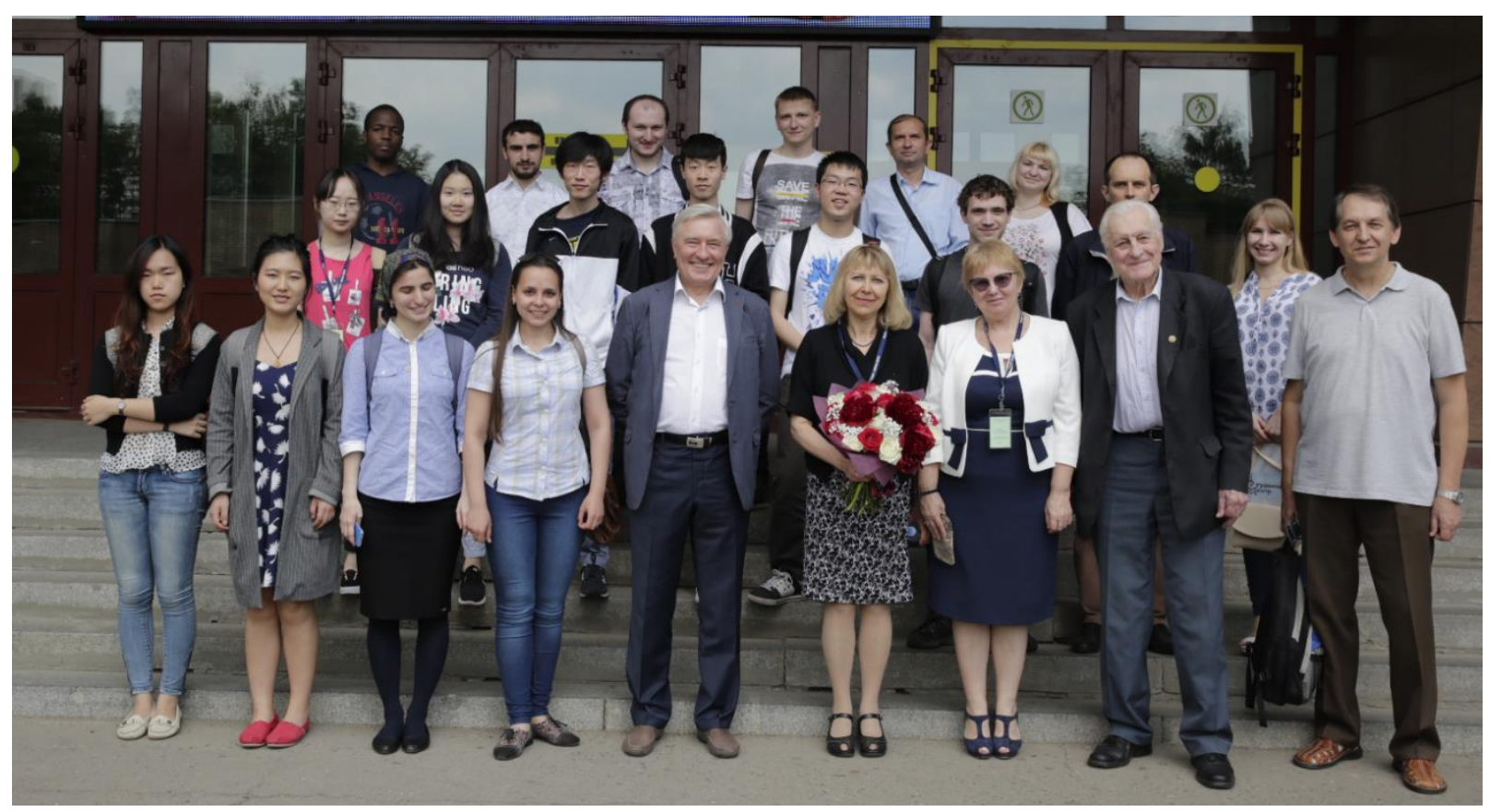

Figure 1. UR and some MEPhI students participants of the International School on Optics and Laser Physics with some professors (first row): Academician Yury Kulchin, Director of the Institute of Automation and Control Processes of RAS; Svetlana Lukishova (UR), the organizer of UR students' participation; Irina Zavestovskaya (MEPhI/LPI), the Dean of the Magistrature; Academician Oleg Krokhin, Scientific Director of Basov's SD of MEPhI and former Director of LPI, and Petr Nikitin, the Head of Laboratory of GPI. 


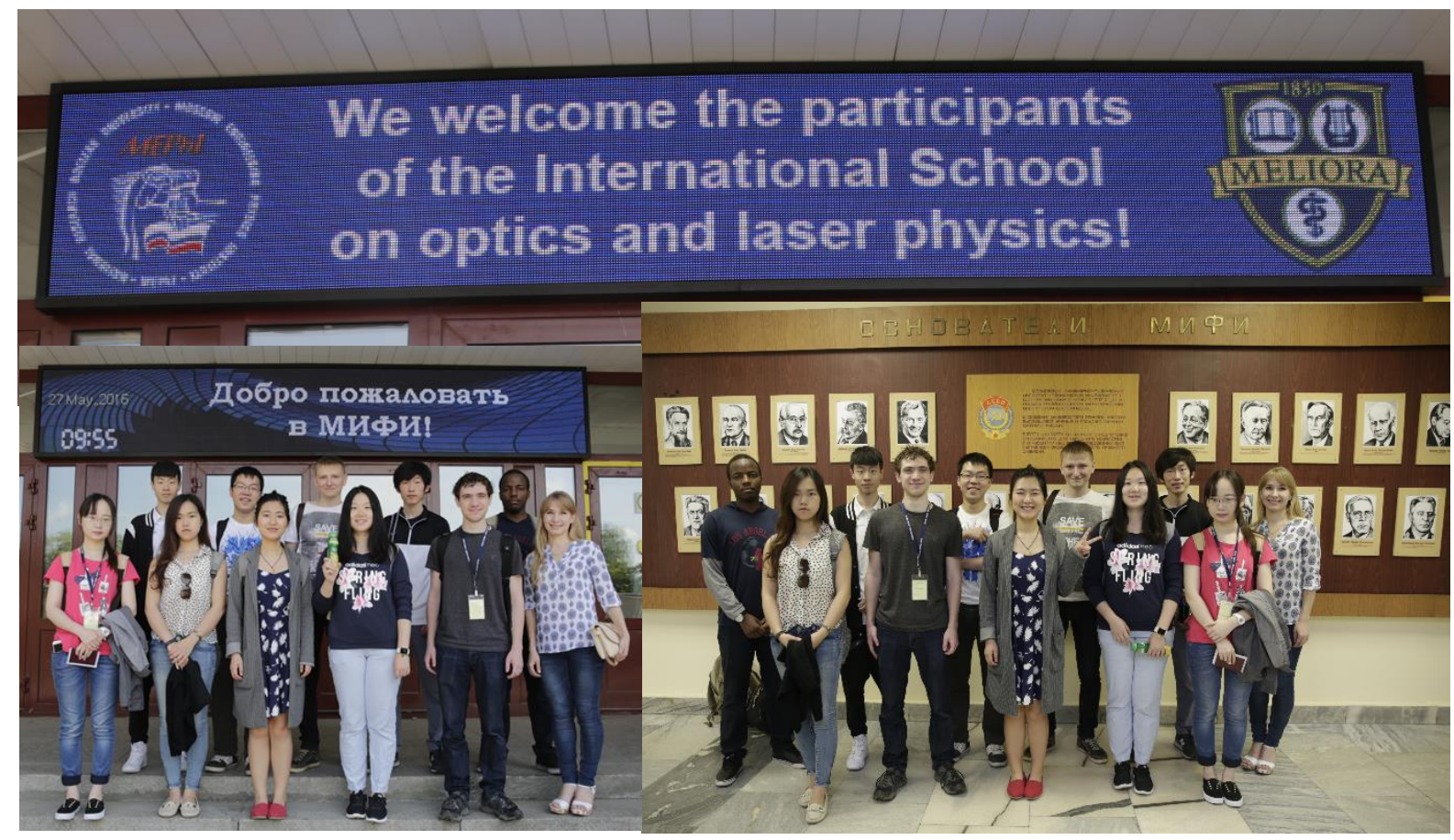

Figure 2. UR students and MEPhI Master's students-organizers. LEFT: At the entrance of the MEPhI administrative building with a poster welcoming them; RIGHT: In front of the poster in a honor of MEPhI founding fathers.

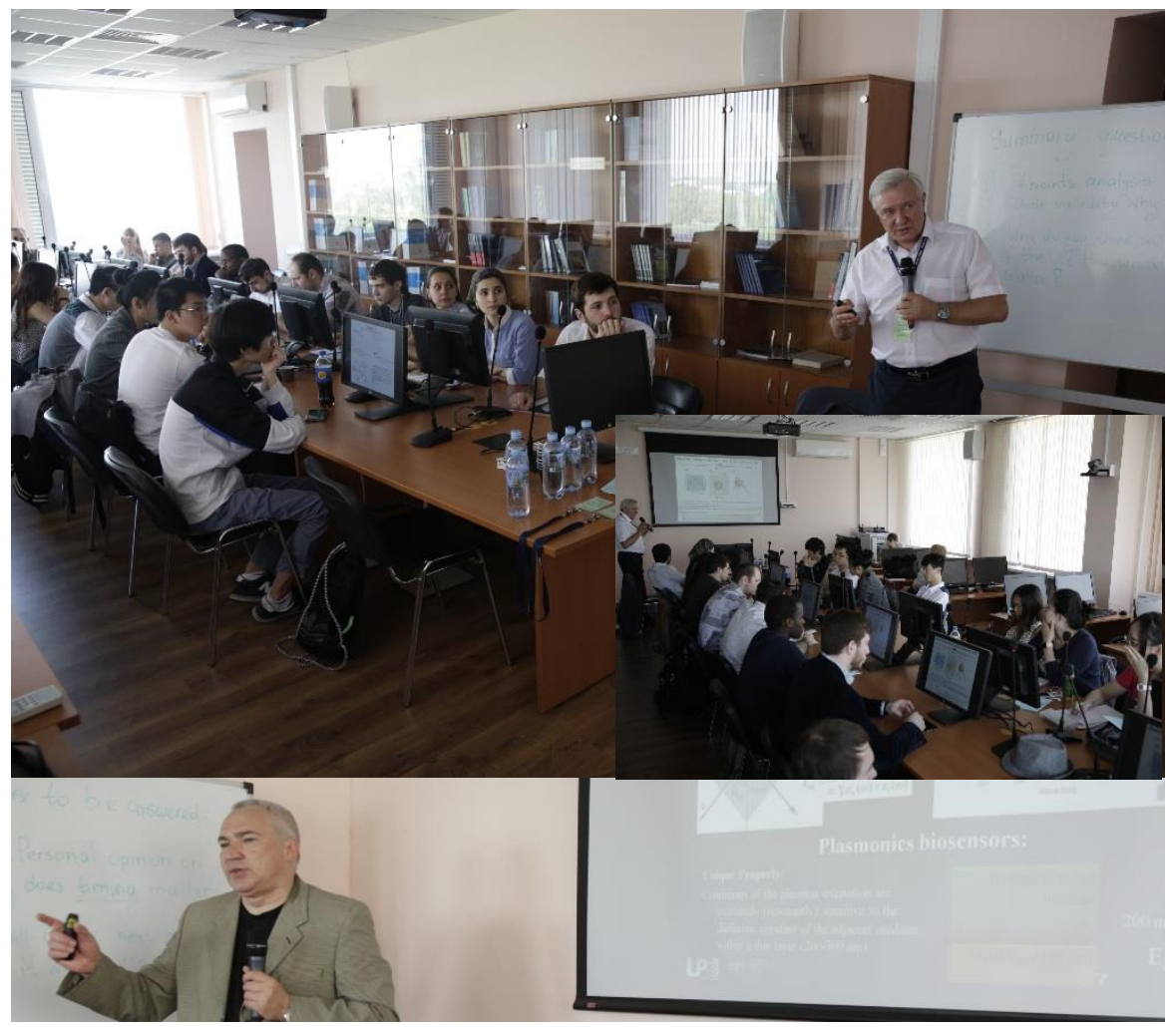

Figure 3. Lectures at the International School on Optics and Laser Physics in MEPhI. 
Below are some UR students' comments about their participation at the MEPhI School:

- $\quad$...The lecture on interference of single photon peaked my attention. It provides the term and equations that are useful at further optical study. The lab tour I like the most of all would be the tour of the laboratories of MEPhI scientific educational center "Nanotechnologies". It is my first time attending a lab focusing on nanotechnology. The equipment used in the lab and the strict condition required for the investigation of all kinds of research opens a brand new world for me...

- $\quad .$. The week was filled knowledge-laden activities that included lectures in MEPhI and Lebedev Physical Institute. The lectures were very enlightening on a variety of topics in the optics field. The most interesting of these lectures for me was the laser thermonuclear fusion which involved energy amplification using the general Lawson's criterion and also involved plasma confinement by magnetic and inertial confinement and research in this area would be vital in the future production of energy. I was also found the lectures on organic nano-photonics and their use in the medical field very interesting in the medical field applications. The labs were held in the evening and they were the highlight of the day as we were able to see cutting edge technology in the field of optics. I was particularly impressed by the quantum radiophysics laboratory in the Lebedev Physical Institute, the different high precision high power lasers and the creation of nanomaterial for use in bioengineering and other nanotechnologies. I applaud the scientific prowess of the laboratories in MEPhI and LPI and I am glad to have witnessed it...

\subsection{Student education in joint research project partnership}

NRNU MEPhI researchers share common interests with some UR groups in different optics and photonics areas, from new photonics nanotechnologies to laser interaction with metals and laser-induced thermonuclear fusion. First collaboration in research started in quantum nanophotonics of diamond between V.I. Konov (MEPhI) and S.G. Lukishova (IO UR) [8] with applications on secure quantum communication and quantum computing. The research of one university complements the research of another (see Figure 4, left). Konov's division prepares CVD diamonds films and nanodiamonds with $\mathrm{SiV}$ single color centers that only a few groups in the word can produce. An excited single color center emits single photons separated in time (antibunching). Lukishova's group prepares gold bowtie plasmonic nanoantennas by a high-precision electron beam lithography. Placing nanodiamonds within a plasmonic nanoantenna gap will enhance single-photon efficiency and a count rate (bit rate) and provide definite polarization of single photons necessary for encoding data in quantum cryptography. The first MEPhI diamond films with SiV-color centers and nanodiamonds from them were investigated on single-photon generation and characterization unit of by the students of Lukishova (see, e.g., Figure 4, center). In addition, MEPhI supported its Master student visiting IO and during one month working in Lukishova's lab as well as carrying out numerical modeling of gold nanoantennas used in the lab (Figure 4, right). The results of this research were presented at MEPhI scientific conference [9]. Figure 5 shows both MEPhI student (left) and IO student (right) at the Lukishova's group single-photon generation and characterization unit.
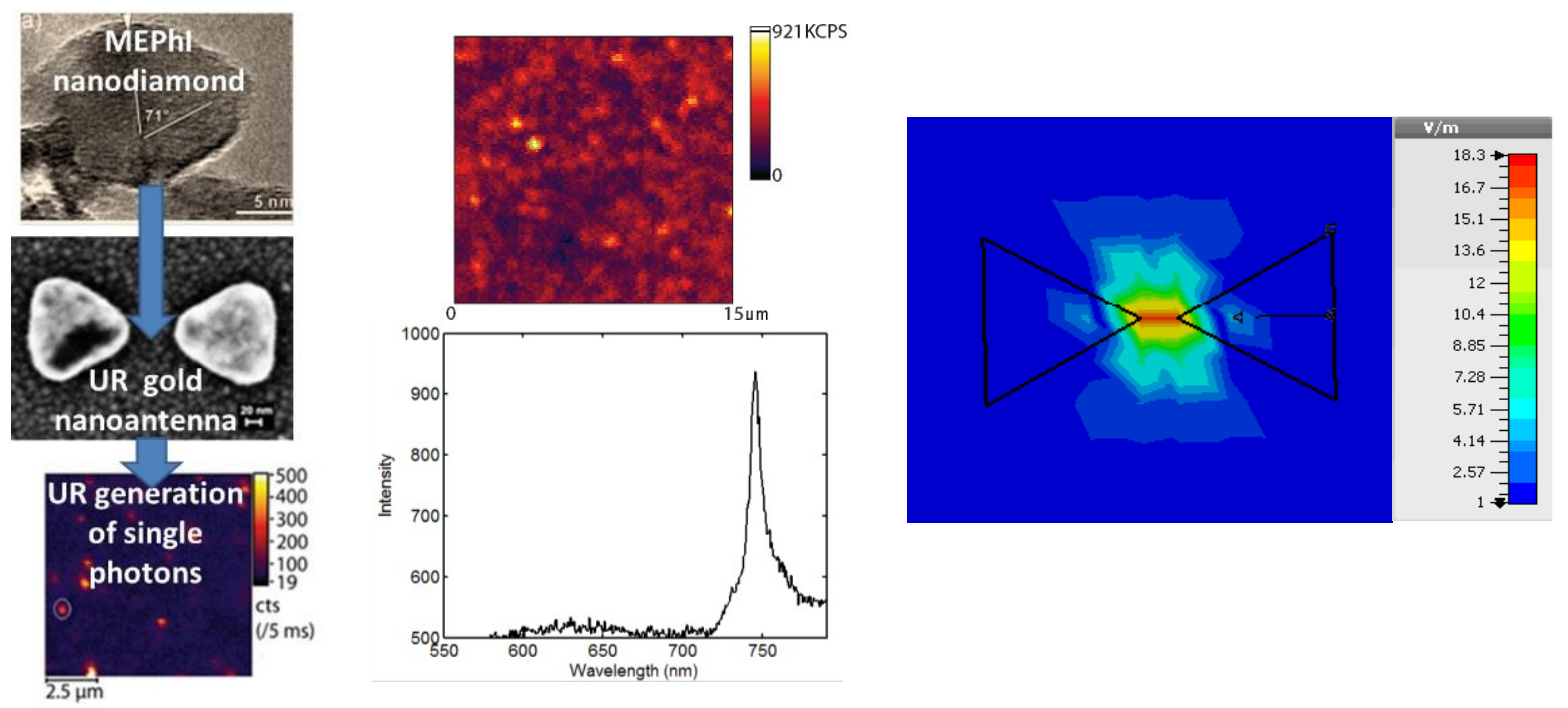

Figure 4. LEFT: Implementation stages of a collaborative project on color-center nanodiamond-based single-photon source. CENTER: Investigation of MEPhI SiV diamond film by the UR Master student (D. Mihaylova). Top - confocal fluorescence microscope imaging at $532 \mathrm{~nm}$ wavelength laser excitation ( $6 \mathrm{ps}$ pulse duration, $76 \mathrm{MHz}$ pulse rep.rate). Bottom - fluorescence spectrum of a $\mathrm{SiV}$ diamond sample. RIGHT: Numerical modeling of a MEPhI Master student (N.A. Khoshooniy), a one-month visitor of the IO UR, showing electric field enhancement by a gold bowtie plasmonic nanoantenna (Lumerical software was used). 
12 other UR students benefited from the collaboration with MEPhI by taking Lukishova's undergraduate/graduate class OPT 253/OPT 453 "Quantum and Nanooptics Laboratory" [10, 11]. Figure 5, right shows students of this class on the lecture on color-center diamonds. In this class UR students wrote essay on practical application of fluorescent diamonds and carried out spectral measurements of diamond films from MEPhI.
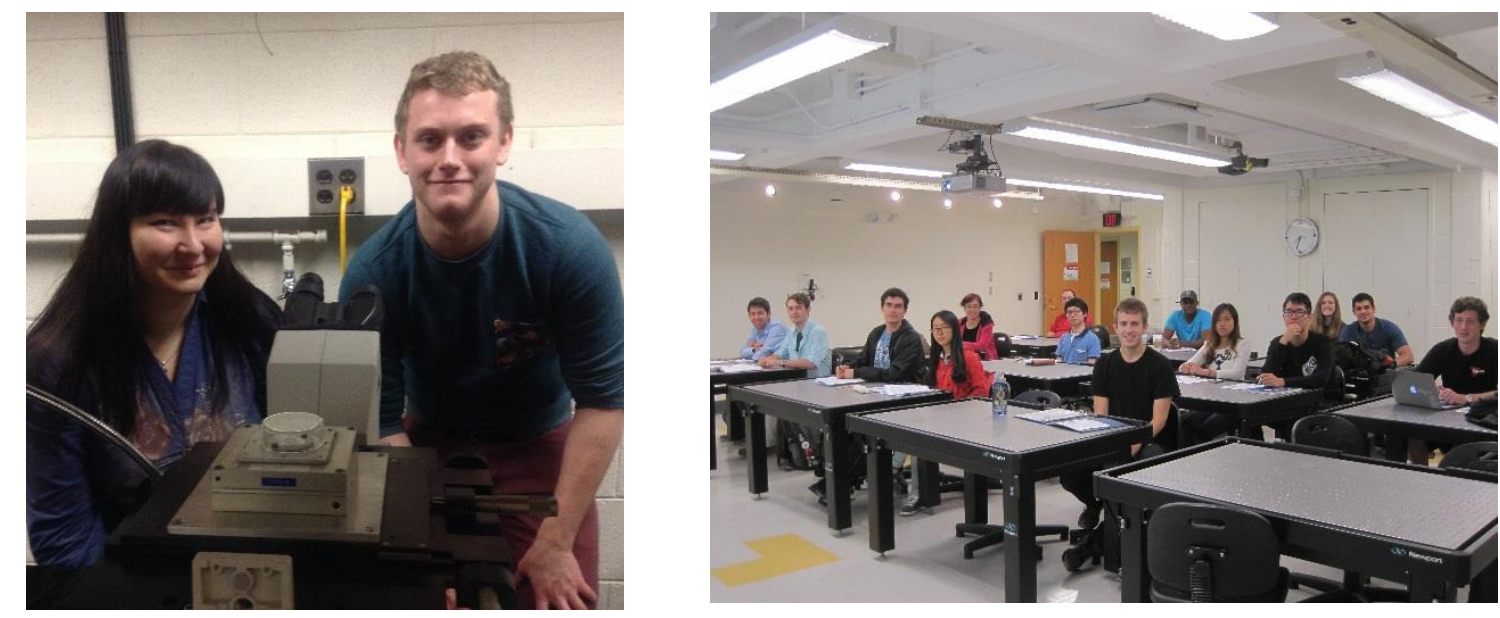

Figure 5. LEFT: MEPhI Master student N.A. Khoshooniy and IO UR senior A. Kruse at single-photon generation and characterization unit of Lukishova's lab. RIGHT: Students of OPT 253/OPT 453 class during Lukishova's lecture on color-center diamonds.

\section{A DOUBLE-DEGREE MASTER'S PROGRAM BETWEEN UR and NRNU MEPhI}

The trend towards global integration of the world economies inevitably leads to integration of educational systems. To succeed in today's global economy, 21 century students should have a high-quality specialization with international experience. There is also an interest of the educational institutions to expand the educational market of their countries. A double-degree Master program provides an opportunity for each party to communicate with different educational system in Science-Technology-Engineering-Mathematics (STEM) and to provide students of both universities studying abroad experience and to acquire cross-cultural understanding.

This program gives students a chance to spend one academic year at each university, UR and NRNU MEPhI, and to receive two degrees, one from each university. We overcame two main challenges of a double Master degree program: (1) High cost education in the US - by waiving $25 \%$ tuition for NRNU MEPhI students by the UR, and NRNU MEPhI students' support by Russian Ministry of Science and Education programs; (2) Low motivation of US students to spend a year in Russia by organizing a Summer scientific camp for UR undergraduate students (future Master students) at NRNU MEPhI (see section 2.1). The double-Master's degree agreement between the UR and NRNU MEPhI was signed in December 2015, and the first Master student of MEPhI was admitted to the UR in Fall 2016.

\section{OTHER COLLABORATIONS IN RESEARCH AND EDUCATION IN OPTICS AND PHOTONICS BETWEEN IO UR AND RUSSIAN INSTITUTIONS}

IO UR has also strong collaboration with another leading Russian university in the field of optics and photonics, ITMO University (St-Petersburg, Russia) (see Ref. [1] and paper of ETOP 2017 [12]). ITMO keeps close links to the Vavilov State Optical Institute (GOI), the oldest and the most comprehensive Soviet optical scientific and defense industry organization, with many professors at ITMO coming from GOI. One of the early outcomes of the UR-ITMO partnership was the creation of the International Institute of Photonics and Optical Information Technologies (IIPOIT) led by the ITMO Dean S.A. Kozlov (ITMO) and the Director of the IO UR X.-C. Zhang. The scientific collaboration involves femtosecond optics and technologies, quantum information technologies, and terahertz (THz) biomedicine. In 2015, the ITMO Rector V.N. Vasilyev visited UR. In 2014 a double-Master's degree program agreement in Optics between UR and ITMO was signed, and 5 ITMO students were awarded UR Master's degrees. In Spring of 2016, N.N. Rozanov (GOI/ITMO), the President of the Russian Optical Society named after Rozhdestvensky (the founder and the first director of GOI) visited UR. 
In further contacts with Russian educational and scientific organizations, in April of 2015, X.-C. Zhang had a meeting at the U.S. National Science Foundation (NSF) with V.Ya. Panchenko, the Charman of the Russian Foundation for Basic Research (=NSF), and NSF program directors about US/Russia joint projects on photonics and THz research. Later (in December of 2015) the International Consortium of THz Photonics and Optoelectronics with 71 partners from 15 countries was established in the Lomonosov Moscow State University (LMSU). V.Ya. Panchenko, LMSU Rector V.A. Sadovnichy, and X.-C. Zhang signed the Memorandum of Understanding (MOU) in Moscow (see Figure 6).
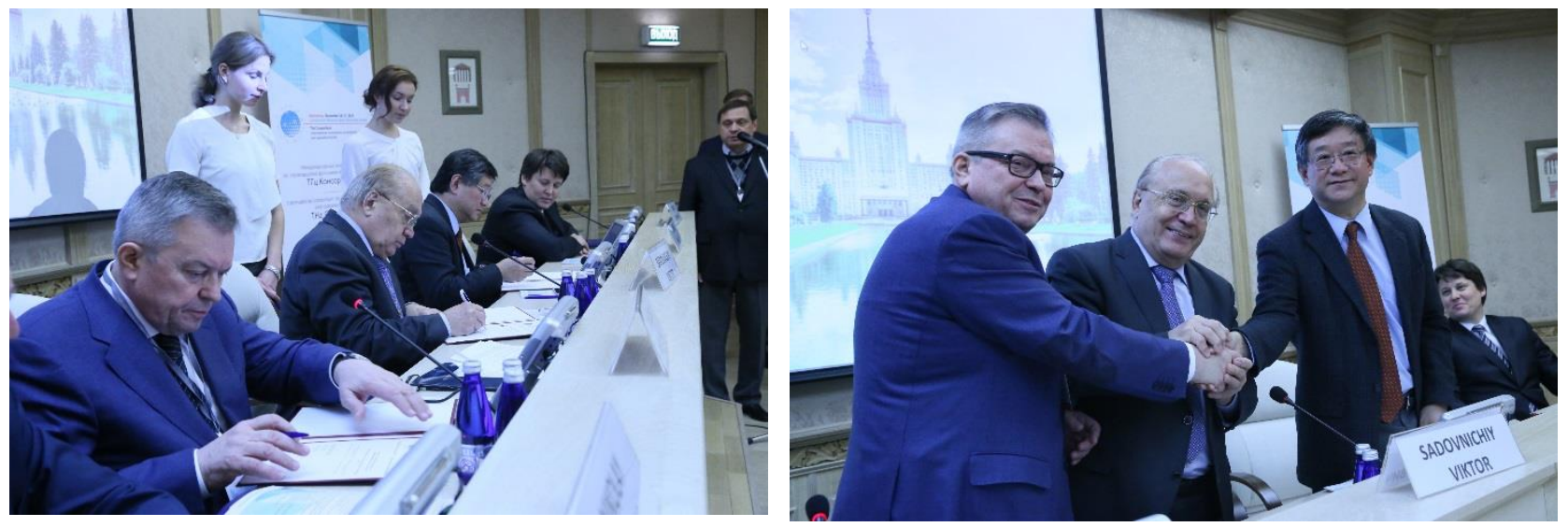

Figure 6. Signing the Memorandum of Understanding in LMSU by V.Ya. Panchenko (left), V.A. Sadovnichy (center) and X.-C. Zhang (right).

\section{CONCLUSION}

This paper describes a growing collaboration in research and education between the oldest optical college in the United States, the Institute of Optics, University of Rochester, and the leading Russian optics and photonics institution National Research Nuclear University MEPhI (Engineering Physics Institute), its Institute of Magistratura, closely connected with the Lebedev Physical Institute and General Physics Institute of the Russian Academy of Sciences.

We hope that U.S./Russia collaborations in Optics and Photonics research and education will continue earlier traditions established by previous generations of optical and laser researchers, when according to John Marburger (the Director of the Office of Science and Technology Policy and the Science Advisor to the President George W. Bush) "contacts between Russian and American workers accelerated the rate of progress" in the field.

With advantages of such a collaboration some questions need to be resolved for its facilitation, for instance, joint government educational programs are necessary. These joint programs can be created with participation of professional societies, e.g. Optical Society OSA or SPIE.

\section{ACKNOWLEDGEMENTS}

We acknowledge the help of D. Smith, A. Vishivanyuk and MEPhI Master students in organizing participation of UR students in the MEPhI School.

For this project S.G.L. was supported by Eurasia Foundation. We also acknowledge the support of the UR and NRNU MEPhI.

\section{REFERENCES}

[1] Lukishova, S.G., Kozlov, S.A., and Zavestovskaya, I.N., “A Rochester-Russia Collaboration”, Optics \& Photonics News, pp. 20-21, November 2016.

[2] www.rochester.edu .

[3] www.optics.rochester.edu .

[4] https://eng.mephi.ru .

[5] www.lebedev.ru/en/. 
[6] Mesyats, G.A., "P.N. Lebedev Physical Institute RAS: past, present, and future”, Physics-Uspekhi 52 (11) 10841097 (2009)

[7] www.gpi.ru/eng/.

[8] Vlasov, I.I., Lukishova, S.G., Konov, V.I., "Nanodiamond single-photon emitters", Plenary Talk, the XII International Workshop on Quantum Optics (Moscow/Troitsk (http://iwqo2015.ru/en/schedule/\#15-aug)).

[9] Khoshooniy, N.A., Kruse, A., Lukishova, S.G., "Bow-tie nanoantennas for single-photon sources based on colorcenters in nanodiamonds", Book of Summaries of the 5 International Young Scientists' School "Modern Problems of Physics and Technology (April 2016, Moscow).

[10] http://www.optics.rochester.edu/workgroups/lukishova/QuantumOpticsLab/.

[11] Lukishova, S.G., "Quantum optics and nano-optics teaching laboratory for the undergraduate curriculum: teaching quantum mechanics and nano-physics with photon counting instrumentation", Paper 100-189, 14th International Conference on Education and Training in Optics \& Photonics (ETOP), May 29-31, 2017, Hangzhou, China.

[12] Egorov, V., Buyanovskaya, E., Melnik, M., Gleim, A. Lukishova, S., Kozlov, S., Zhang, X.-C., "Research summer camp in photonics", paper 100-59, 14th International Conference on Education and Training in Optics \& Photonics (ETOP), May 29-31, 2017, Hangzhou, China. 